\title{
KRITIK METODE KONTEKSTUALISASI PENAFSIRAN AL-QUR'ÂN ABDULLAH SAEED
}

\author{
Imron Mustofa \\ Sekolah Tinggi Agama Islam YPBWI, Indonesia \\ E-mail: stofa27@yahoo.com
}

\begin{abstract}
This article examines the growing movement of thought today, which later becomes known as modernist Islamic thought, especially the idea Abdullah Saeed. For him, a critical attitude towards the source and content of knowledge is necessary internal criticism of Islamic society. This study tries to present data relating to the role of reason behind the idea. Critical reading towards logical framework and epistemology is needed to contextualize dogma, tradition, and culture in order to be transformed to the present. This research gives birth to the perspective that the modernization of Islamic thought is a systematic movement regarding Islamic issues in the ever-changing context. Its characteristics is colored by emphasis on rationality free from sectarianism or exclusivism without claiming finality of thinking. Making interconnectivity (historical context) is the main barometer of interpretation process. The article reveals that Saeed's strategies include four main phases; encounter with the world of the text, critical analysis; meaning for the first recipients and ending with text relating to the up to date context. However, excessive exaltation of contextuality will lead to the emergence of an indigenization of the Qur'an, and even Islam in general.
\end{abstract}

Keywords: Contextuality; modernization; rationality; Islamic thought.

\section{Pendahuluan}

Al-Qur'ân sebagai basis dasar Islamic thought merupakan topik yang selalu update untuk didiskusikan. Semenjak "kelahiran"nya di Makkah tahun $610 \mathrm{M}$ sampai saat ini, ia selalu disambut dengan ragam perdebatan akan sejarah, relevansi, fleksibelitas ajaran, sumbangsih keilmuan, framework, bahkan autentisitas pemikiran yang dibangun. Menu kajian ini bukan hanya tokoh, teologi, hukum, kandungan makna ataupun posisinya sebagai kitab undang-undang dasar, namun 
juga mencakup pemikiran politik, estetika, pengalaman intuitif, bahkan terobosan pendekatan filosofis yang dibangun darinya. Baik melalui jalur pengalaman mistik (intuisi/'irfanî) ataupun melalui pendalaman terhadap persoalan-persoalan yang selama ini baru mampu dijawab oleh intelektualitas logika.

Ada banyak pemikir yang mencoba membahas diskursus ini, salah satunya adalah Abdullah Saeed. Ia berusaha melihat bangunan Islam melalui perspektif metodologis dalam studi al-Qur'ân, bahkan mencoba menelurkan perspektifnya tersebut ke dalam pandangan umum yang berkaitan dengan Islam secara holistik. ${ }^{1}$ Poin inilah, yang selanjutnya melahirkan karya yang dinamai dengan Islamic Thought: An Introduction ataupun Reading the Qur'an in the Twenty-First Century. Menilik tema Islamic Thought dan Twenty-First Century yang termaktub dalam judul buku tersebut, timbul di benak penulis pertanyaan: Bagaimanakah Saeed menyajikan sebuah "pembacaan baru" terhadap Islamic thought? Apa kaitannya dengan realita kehidupan kekinian? Apa relevansinya dengan proses modernisasi? Di mana letak perbedaan antara yang ditawarkan dengan pendekatan lain yang telah ada sebelumnya? Serta bagaimana bentuk tawaran analisa al-Qur'ân yang disuguhkan Saeed sebagai dasar modernisasi pemikiran Islam? Pertanyaan-pertanyaan inilah yang akan penulis coba cari jawabannya dalam diskursus kali ini. Selain ide pokok tersebut, penulis akan mencoba membaca bagaimana pendekatan yang digunakan dalam merumuskan persoalan ini. Oleh karena itu, menjadi penting kiranya untuk memulai penyelidikan ini dengan sebuah telaah tentang makna modernisasi ataupun pemikiran Islam serta review singkat tentang kehidupan Saeed.

\section{Biografi Singkat Abdullah Saeed}

Abdullah Saeed atau biasa dipanggil Saeed merupakan guru besar Studi Arab dan Islam di Melbourne University, Australia. Ia juga menjabat Direktur Pusat Studi Islam Kontemporer di Universitas yang sama. Saeed kecil lahir di Maldives, 25 September 1964. Dunia pendidikannya diwarnai oleh studi dalam bahasa Arab dan Studi keislaman di Islamic University of Madina, 1971-1986. Tahun berikutnya Saeed mengembara ke Australia. Di sini, profesor kelahiran

\footnotetext{
1 Abdullah Saeed, Interpreting the Qur'an: Towards A Contemporary Approach (New York: Routledge, 2006), Reading the Qur'an in the Twenty-First Century: A Contextualist Approach (New York: Routledge, 2013), The Qur'an: An Introduction (New York: Routledge, 2008).
} 
53 tahun silam mengajar Studi Arab dan Islam. Selain bahasa Arab, Saeed juga mengusai Bahasa Inggris, Maldivia, Urdu, Jerman bahkan bahasa Indonesia. Berbekal ini semua, ia sering mengunjungi Amerika, Eropa, Timur Tengah, Asia Selatan dan Asia Tenggara.

Saeed merupakan seorang penulis prolifik. Ini terlihat dalam beberapa karyanya seperti: Reading the Qur'an in the Twenty-First Century: A Contextualist Approach (New York: Routledge, 2013); The Qur'an: An Introduction (New York: Routledge, 2008); Islam in Australia (Sydney: Allen dan Unwin, 2003); Freedom of Religion: Apostasy and Islam (Ashgate Pub Ltd, 2004); Islamic Banking and Interest: A Study of the Probibition of Riba in Islam and its Contemporary Interpretation (Leiden: E. J. Brill, 1996); Essential Dictionary of Islamic Thought (Adelaide: Seaview Press, 2001); Islamic Thought: An Introduction (New York: Routledge, 2006); serta beberapa artikel: "Islamic Reform: Salafiya, Modernism and Revival," dalam John L. Esposito dan Emad Sahin (eds.), Oxford Handbook of Islam and Politics. Oxford: Oxford University Press; "Premodern Islamic Legal Restrictions on Freedom of Religion, with Particular Reference to Apostasy and its Punishment," dalam Anver Emon et. al. (ed.), Islamic Law and International Human Rights Law: Searching for Common Ground?. New York: Oxford University Press. 2012; "History of Sukuk: Pragmatic and Idealist Approaches to Structuring Sukuk," (Saeed dan Salah), dalam Ariff, Iqbal dan Mohamad (eds.), The Islamic Debt Market for Sukuk Securities: The Theory and Practice of Profit Sharing Investment. Cheltenham (United Kingdom: Edward Elgar Publishing. 2012); "The Self-Perception and the Originality of the Qur'an: Qur'an 2:23-24; 3:44; 10:15; 69:38-47," dalam David Marshall (ed.) with an Afterword by Rowan Williams, Communicating the Word: Revelation, Translation, and Interpretation in Christianity and Islam (Washington: Georgetown University Press, 2011); "Rethinking Classical Muslim Law of Apostasy and the Death Penalty," dalam Paul Marshall dan Nina Shea (eds.), Silenced (Oxford: Oxford University Press, 2011) dan beberapa karya lainnya. Dari sekian karya tersebut, buku Islamic Thought: An Introduction sebagaimana disebut di atas merupakan buku yang menarik perhatian penulis.

\section{Definisi Modernisasi dan Kontekstualisasi}

Ada dua tema penting yang perlu dikaji lebih lanjut, yaitu: a) modernisasi pemikiran; dan b) kontekstualisasi. Makna dari istilah pertama, "modernisasi" merupakan sebuah ungkapan yang dibangun 
dari terma "modern" dan tambahan "-sasi." Dari segi bahasa

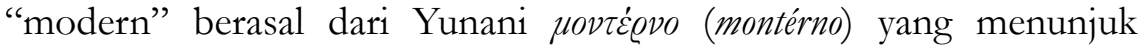
makna denotasi keadaan kekinian. Tambahan "-sasi" menjadikannya sebagai sebuah proses yang menilik segala sesuatu dalam perspektif kekinian. Anne L. Birberick mendeskripsikan "modern" sebagai a curious concept that signifies both the sameness and difference in history, allowing bistorians to understand their own times by practicing genealogies. ${ }^{2}$ Terjemahan bebasnya, suatu konsep yang ingin mengetahui persamaan dan perbedaan kondisi dalam sejarah, memberikan pemahaman pada ahli sejarah tentang keadaan pada masa lampau dengan jalan mempelajari silsilah. Singkatnya, "modern" merupakan suatu istilah yang merujuk pada suatu anggapan, sikap ataupun perilaku yang mengkaji, mendalami serta mempertanyakan problematika masa lampau. Darinya akan didapati beberapa pandangan ataupun ide yang dapat lebih lanjut dikaji, diuji dan dipertanyakan validitas serta tingkat keabsahan untuk diterapkan pada masa ini. ${ }^{3}$ Oleh karena itu, tidak jarang hal ini sering diidentikkan dengan zaman teknologi dan perkembangan.

Ada beberapa terma hasil derivasi dari kata "modern", sebut saja modernisasi, modernisme, modernitas dan beberapa istilah lain yang sering dipergunakan dalam keseharian. Perubahan bentuk ataupun makna beberapa istilah ini sering kali berandil besar dalam pergeseran ataupun pengaburan makna awalnya. Untuk itu penulis tegaskan di sini, bahwa modern[isasi] sebagai proses pemutakhiran atau era yang berkorelasi dengan/serta mencakup makna baru seperti inovatif, perkembangan, kemajuan dan perubahan. Jika terma-terma tersebut mewakili persamaan makna dari modern, maka antonim dari kata tersebut adalah tradisional, antik, konservatif dan kuno. Meskipun demikian, perlu diketahui apa yang disebut sebagai modern dalam satu kurun waktu ataupun tempat tertentu tidak mungkin memiliki arti yang sama dengan kondisi lain, terlebih lagi kaitannya dengan budaya dan pemikiran.

Jika ditambahkan kata "pemikiran Islam" ke dalam modernisasi, maka modernisasi di sini menjadi suatu pemikiran Islam dalam jangka panjang yang sangat berkaitan dengan perspektif atau kerangka kerja (framework) dari apa yang disebut inovatif, berkembang, berubah dan

2 Anne L. Birberick, et. al., Modern Perspectives on the Early Modern: Temps Recherché, Temps Retrowvé (Virginia: Rookwood Press, 2005), 150.

${ }^{3}$ Deliar Noer, Gerakan Modern Islam di Indonesia 1900-1942 (Jakarta: LP3S, 1996), 12. 
adaptatif. Oleh karenanya, standar penilaian "modernisasi pemikiran Islam" menjadi sangat relatif dan dipengaruhi oleh situasi, kondisi dan "mata" orang yang memandang. Satu fenomena bisa menjadi sangat berbeda dalam pandangan aktor berbeda pula. Lantas, bagaimana Saeed mendeskripsikan modern ataupun modernisasi pemikiran Islam? Dalam Islamic Thought: An Introduction, Saeed menulis:

Modernists called for systematic thinking about Islamic legal issues without claiming finality. This involved making a clear distinction between the shari'a and figh, in order to distinguish between the permanence of the shari'a represented by the Qur'an and Sunna and the "mutability" of figh. Additionally, modernists sought to avoid sectarianism and the exclusiveness of legal and theological schools by not necessarily following the specific legal rulings and solutions of any particular school. ${ }^{4}$

Matrik tersebut dengan jelas menegaskan bahwa modernisasi pemikiran Islam versi Saeed merupakan suatu cara pandang sistematis terhadap isu-isu dalam Islam yang selalu berubah sesuai konteksnya, tanpa diikuti klaim "penutup (finality)". Penekanannya terletak pada kata without claiming finality/tidak ada klaim penutup. Segala sesuatu yang berkaitan dengan pemikiran dalam Islam harus dapat dan "wajib" untuk berkembang, berevolusi atau bahkan berubah. Satusatunya yang tidak berubah adalah perubahan itu sendiri. Sebab bagi Saeed, klaim "penutup (finality)" dalam pemikiran adalah suatu hal yang "kuno".

Perspektif tersebut agaknya merupakan pengembangan dari pendapat Ignaz Goldziher, yang menyebut bahwa setiap individu maupun kelompok manapun akan mencari justifikasi dan legitimasi dalam Kitab Suci ataupun karya lain yang dilahirkan oleh para generasi awalnya, tidak terkecuali Islam..$^{5} \mathrm{Di}$ sini ada dua hal yang perlu dicermati: Pertama, jika disandingkan kedua ide tokoh tersebut, maka tidak berlebihan kiranya kalau dikatakan bahwa Saeed telah mencoba mengadopsi ide "mencari justifikasi dan legistimasi dalam kitab suci" milik Goldziher, menjadi klaim "penutup (finality)" atau dalam bahasa lain, batas akhir dari suatu validitas kebenaran. Kedua, secara logis, baik ungkapan Goldziher ataupun Saeed apabila diteruskan lebih jauh, tidak mustahil akan ditemukan suatu titik di mana statemen keduanya menimbulkan permasalahan yang pelik.

${ }^{4}$ Abdullah Saeed, Islamic Thought: An Introduction (New York: Routledge, 2006), 54.

${ }^{5}$ Ignaz Goldziher, Madhâhib al-Tafsîr al-Islâmî (Kairo: Maktabah al-Khaniji, 1955), 3. 
Suatu misal, titik di mana jawaban yang dicari sebagai dasar legitimasi dan justifikasi tidak ditemukan, lantaran keterbatasan "teks suci" ataupun kelemahan dari segi pembacanya. Tentunya ini menjadi suatu pukulan telak dalam proses negosiasi dengan perubahan kekinian semacam globalisasi, kemajuan sains-teknologi, penemuan arkeologis, genetika, bunga bank serta perkembangan penduduk. Alternatif jawaban dari hal itu akan berkisar antara pernyataan bahwa teks tidak cukup komprehensif menjawab perkembangan zaman; atau konteks dari nașs sifatnya adaptif untuk semua situasi dan kondisi, meskipun hal tersebut tidak tertuang secara eksplisit dalam nass. Sebagai seorang Muslim, Saeed tampaknya cenderung kepada pilihan yang kedua. Karenanya, ia sangat mengagungkan prinsip kontekstual dalam pemahaman teks.

Makna dari istilah kedua, "kontekstualisasi" yang gabungan dari "konteks/contexl", menunjukkan denotasi arti hubungan, keadaan atau kondisi di mana suatu keadaan terjadi. ${ }^{6}$ Tambahan "-tualisasi" yang bermakna proses menjadikannya berkonotasi proses keterhubungan suatu hal dengan elemen lainnya. Gillian Brown mengartikan konteks sebagai lingkungan, tempat atau keadaan di mana suatu bahasa dipergunakan. ${ }^{7}$ Berbeda dengan Brown, Glenn F. Stillar menilai konteks sebagai sesuatu yang accompanying text, ${ }^{8}$ yaitu sesuatu yang inheren dan hadir bersama teks. Paul Warren mendefinisikan konteks sebagai suatu aspek baik lingkungan fisik atau sosial yang memiliki keterkaitan dengan hal ataupun uraian yang berperan sebagai suatu penjelas dari pengetahuan yang berasal dari percakapan (memiliki author/speaker dan reader/listener), sehingga pendengar mampu memahami apa yang dimaksud pembicara. ${ }^{9}$

Adapun bagaimana Saeed mengartikan kontekstual, dapat dilihat dalam kutipan pernyataannya dalam Islamic Thought: An Introduction, di sini ia menegaskan:

The contextualists emphasize both the socio-historical context of the

Qur'an and its subsequent interpretation. They argue for under-

6 Richard Marius (int.), Random House Webster's College Dictionary (New York: McGraw-Hill, 1991), 294.

${ }^{7}$ Gillian Brown, et. al., Discourse Analysis (Cambridge: Cambridge University, 1984), 25-26.

8 Glenn F. Stillar, Analyzing Everyday Texts: Discourse, Rhetoric, and Social Perspectives (London: SAGE, 1998), 52.

${ }^{9}$ Paul Warren, et. al. (ed.), Context and Semantics for Knowledge Management (New York: Springer, 2011), 5. 
standing the ethico-legal content in the light of the political, social, historical, religious and economic contexts in which this content was revealed, understood, interpreted and applied. They ask for a high degree of freedom for the modern Muslim scholar in arriving at what is mutable (changeable) and immutable (unchangedable) in the ethicolegal content... They represent an important step in relating the Qur'anic text to the contemporary needs.. [pen.: and] relies heavily on understanding the historical context of the revelation at the macro level, and then relating it to a particular need of the modern period. ${ }^{10}$

Melalui kutipan tersebut nampak jelas bahwa apa yang Saeed maksud dengan lafal kontektual[-isasi] adalah sebuah "proses mencari" keterikatan antara aspek "kandungan" sosio-historis dalam al-Qur'ân dengan produk penafsiran para ulama Klasik. Oleh karenanya untuk mendapatkan benang merah dari suatu persoalan, maka diperlukan sebuah kebebasan dalam menentukan mana yang mutable (changable/al-mutaghayyirât) serta mana yang immutable (unchangeable/al-thawâbit).

Merangkum beberapa pendapat di atas, dapat disimpulkan bahwa konteks merupakan situasi atau latar belakang terjadinya suatu komunikasi. Artinya, jika dikatakan sesuatu "menurut konteksnya", maka artinya suatu hal dianggap sebagai sebab ataupun alasan terjadinya suatu dialog. Contoh singkat peran konteks dialog dalam analisa makna: pernyataan "saya ingin turun, sudah capek". Kata "turun" jika diucapkan oleh pejabat, maknanya bisa berarti "turun jabatan". Namun tidak demikian jika yang mengucapkannya adalah anak kecil, sebab pengertiannya bisa berubah drastis, maka "turun" dalam kalimat yang dicontohkan bisa saja yang dimaksudkan adalah "turun dari pohon". Singkat kata, untuk mendapatkan pemahaman wacana yang menyeluruh, konteks harus dipahami dan dianalisa secara mutlak, sehingga segala hal yang berhubungan dengan "teks", baik itu berkaitan dengan arti, maksud maupun informasinya. Tergantung pada konteks yang melatari peristiwa di balik teks.

Teks yang dimaksud dalam keterangan di atas bukan semata teks yang dituangkan dalam bentuk tulisan dan perkataan, termasuk mencakup segala fenomena non-verbal, bahkan segala hal termasuk lingkungan di mana hal itu berada. Lebih lanjut, Syafi'e mengklasifikasikan konteks ke dalam empat macam: "linguistik" yang berkaitan dengan untaian kalimat dalam perkataan ataupun tulisan. Di sini struktur bahasa dan wujud pemakaian kalimat tertentu sangat

${ }^{10}$ Saeed, Islamic Thought, 31-32. 
berpengaruh; "fisik" yang meliputi tempat kejadian, objek yang dibahas serta tindakan para partisipan; "sosial," yaitu relasi sosiokultural yang melengkapi hubungan antar-partisipan dalam komunikasi; terkahir, konteks "epistemis" atau latar belakang pengetahuan yang sudah dimaklumi bersama antara speaker (penutur) dan listener (pendengar). ${ }^{11}$ Artinya, kontekstual merupakan suatu keterikatan atau interkoneksi antara teks dengan konteks dari fakta historis.

Dari pemaparan di atas dapat disimpulkan, dalam perspektif Saeed, Muslim modernis adalah seorang yang memandang perubahan sosial-keagamaan serta dinamika kehidupan kontemporer harus dihadapi dengan metodologi pemikiran yang menghubungkan antara paradigma pemikiran klasik dan metodologi kajian keislaman kontemporer. Selan itu, ciri seorang modernis adalah menghindari sektarian, keekskulusifan mazhab pemikiran serta tidak mengklaim final produk pemikirannya. Mereka berusaha melakukan reinterpretasi al-Qur'ân sebagimana yang Saeed sebut fresh interpretation, ${ }^{12}$ dengan coraknya yang kontekstual-historis.

\section{Interkoneksi sebagai Cara Berpikir}

Saeed memandang pentingnya konteks al-Qur'ân dalam penafsiran, karena melihat hubungan antara kandungan makna teks sangat adaptif sesuai dengan situasi dan kondisi, meskipun hal tersebut tidak tertuang secara eksplisit dari teks yang ada. Ini tampaknya melatarbelakangi Saeed untuk lebih bersemangat dalam mengusung interkoneksi historis sebagai sebuah cara berpikir dalam studi keislaman yang paling mutakhir. Oleh karena itu, dalam karyanya Interpreting the Qur'an: Towards A Contemporary Approach, tepatnya pada bagian pendahuluan, Saeed tampak mencoba untuk menunjukkan bahwa hampir semua aspek pemikiran Islam sangat terbuka untuk dikaji lebih mendalam melalui pendekatan kontekstual. Dalam karya yang diterbitkan oleh Routledge tahun 2006 ini, Saeed menilai bahwa pendekatan yang paling "ramah" terhadap diskursus keilmuan Islam adalah pendekatan kontekstual alias keterhubugan elemen khususnya dalam aspek sosio-historis. Ia menulis:

...more flexible approach to interpretation of these texts by taking consideration both the socio-historical context of the Qur'an at the time of revelation in the first/seventh century and the contemporary

${ }^{11}$ Imam Syafe'ie, Retorika dalam Menulis (Jakarta: Dependikbud, 1988), 126.

12 Ibid., 152. 
concerns and needs of Muslims today. My main interest is how the meaning of the Qur'an can be related to the life of the Muslim, in a sense its application to day-to-day practicalities in different times, circumstances and places, particularly as it relates the concerns and needs of the modern period. ${ }^{13}$

Matrik di atas, setidaknya telah menjawab soal bagaimanakah pendekatan kajian al-Qur'ân atau keislaman secara umum yang paling mewakili perspektif Saeed? Baginya kontekstual berarti suatu kerangka kerja (framework) yang tidak bisa dihindari dalam studi keislaman. Ungkapnya, this case, which received international exposure, shows that modern badith scholarship is as relevant today as it ever was. ${ }^{14}$ Implikasinya, segala kandungan ataupun makna "teks" dalam alQur'ân harus dikembalikan ke dalam interkoneksi kandungan makna, tema kajian, kesatuan pemahaman antar-partisipan dan sejarah.

Kenapa keterikatan teks dengan keempat hal tersebut penting? Saeed menegaskan, teks harus mampu menyesuaikan diri dengan circumstances and places, particularly as it relates the concerns and needs of the modern period. ${ }^{15}$ Baginya, tradisi keilmuan Islam-termasuk sumbersumbernya-harus mampu mengakomodir segala bentuk situasi dan kondisi, khusunya yang berhubungan dengan keinginan dan kebutuhan di era modern. Di sini Saeed memandang interkoneksi historis merupakan suatu cara pandang yang paling "tajam" dalam membedah segala diskursus keilmuan dalam Islam. Sebagaimana sering ditekankan oleh Saeed, bahwa diskursus keilmuan Islam sudah sepatutnya mampu menyuguhkan dialog kontekstual antara Islamic thought in both the pre-modern and modern periods, ${ }^{16}$ karenanya seorang modernis harus selalu "berburu" suatu cara berpikir yang baru, yang mampu menghubungkan seluruh aspek sosio-kultural dengan alQur'ân sebagi teks.

Dengan slogan "mendialogkan cara berpikir agama dengan ilmu modern", Saeed merumuskan tujuh kriteria yang harus dimiliki seorang modernis: a) lebih berfokus pada interkoneksi teks dengan konteks serta dinamika sosio-kultural. Mereka memandang perlu adanya reformasi substansial dalam produk pemikiran klasik guna menyesuaikan dengan kebutuhan Muslim saat ini. Oleh karenanya, perlu metode baru dalam interpretasi teks; b) menyadari ada banyak

${ }^{13}$ Saeed, Interpreting the Qur'an, 1.

${ }^{14}$ Saeed, Islamic Thought, 41-42.

${ }^{15}$ Saeed, Interpreting the Quran, 1.

${ }^{16}$ Saeed, Islamic Thought, i, vii, 10, 13, 30. 
topik persoalan yang tidak termaktub dalam al-Qur'ân; c) mengedepankan prinsip-prinsip keadilan, kejujuran serta kasih sayang dalam proses pembacaan teks: d) memahami al-Qur'ân memiliki hierarki prinsip dan nilai hidup; ${ }^{17}$ e) meyakini akan diperbolehkannya pengambilan misal fenomena konkret dalam suatu generasi untuk generasi selainnya (qiyâs); f) meneliti dan berhati-hati dalam mengaitkan fakta empiris dengan teks baik wahyu maupun produk penafsiran terdahulu; dan g) berfokus untuk menjawab tantangan dan kebutuhan Muslim kontemporer. ${ }^{18}$ Darinya dapat disimpulkan bahwa seorang modernis dalam pemikiran Islam harus mampu menyajikan jawaban terkait problematika kekinian melalui interkoneksi model interpretasi warisan ulama klasik dengan metodologi keilmuan kontemporer.

Secara operasional cara kerjanya mencakup: a) proses pencarian dasar teks (encounter with the world of the text); b) analisa kritis (critical analysis) atas kandungan makna, tema kajian, kesatuan pemahaman antar-partisipan dan sejarah teks yang termaktub; c) proses identifikasi atas apa yang dimaui teks oleh penafsir pertama (meaning for the first Recipients) tentang permasalahan tersebut; dan d) mengakhiri dengan menghubungkan teks itu dengan konteks sosio-historis kekinian (relating text to the present context), sehingga hasil pemahaman terhadap teks tetap aktual untuk diterapkan. ${ }^{19}$ Singkatnya, diawali dengan proses memahami teks dan konteks sosio-historisnya, kemudian diikuti dengan proses realisasi.

Keempat proses di atas oleh Saeed digolongkan ke dalam kelompok context-based ijtihad. Model ijtihad semacam ini mencoba memahami fenomena konteks kekinian teks melalui studi sejarah pada masalah-masalah hukum dalam konteks masa lalu. Ia berbeda dengan

\footnotetext{
${ }^{17}$ Bagi Saeed ada lima hierarki nilai, antara lain: 1). Nilai yang bersifat kewajiban. Ini tidak berubah, namun selalu menjadi dogma, seperti persoalan teologi, praktik ibadah dan halal-haram; 2). Nilai fundamental yaitu nilai kemanusiaan dasar; hifz aldîn, al-nafs, al-nasl, al-mâl dan al-'aql; 3). Nilai proteksional yang berperan menjaga keberlangsungan nilai fundamental; 4). Nilai implementasional, fungsinya merealisir nilai proteksional; dan 5). Nilai instruksional, yang merupakan barometer perbuatan manusia. Ia diekstrak dari kandungan makna al-Qur'ân, khususnya tentang fenomena yang berlaku khusus pada zaman kenabian. Saeed, Interpreting The Qur'an, 130.

18 Ibid., 90-101; 118-120; 126-144. Ahmad Imam Mawardi, "Muslim Progresif dan Ijtihad Progresif dalam Pandangan Abdullah Saeed," dalam Tolhatul Choir, Islam dalam Berbagai Pembacaan Kontemporer (Yogyakarta: Pustaka Pelajar, 2009), 537.

${ }^{19}$ Saeed, Islamic Thought, 55-56, 150-152.
} 
dua model lainnya, yaitu: text-based ijtibad atau model klasik tradisonalis, dan eclectic ijtihad. Dalam text-based ijtihad, teks memegang kendali dan berkuasa penuh, baik itu al-Qur'ân, Sunnah ataupun pendapat ulama generasi awal. Ciri khasnya adalah adanya dominasi metode ijmấ dan qiyâs dalam pengambilan hukum. Adapun dalam eclectic ijtihad, prosesnya mencakup pemilihan teks yang dirasa lebih mendukung pendapat yang diyakini. Model ini dapat disebut sebagai model ijtihad dengan metode akumulasi data yang pro afiliasi penafsir. Ciri khasnya alih-alih sebagai proses pencarian kebenaran, namun lebih kepada justifikasi ide subjektif.

Sebagai contoh, Saeed menggunakan metodenya dalam menafsiri ayat ketika menjukkan respons perbedaan pendapat tentang riba. Jika ulama klasik menginterpretasi pengharaman riba sebagai suatu penjelasan final dan menolak tersedianya ruang untuk mereinterpretasi hukum, maka tidak demikian bagi Saeed. Ia secara lantang berani meneriakkan legalisasi praktik bunga bank konvensional. Menurutnya, dalam menginterpretasi ayat-ayat riba perlu pemetaan "kebutuhan" debitur ke dalam pinjaman produktif dan konsumtif. ${ }^{20}$ Klasifikasi ini akan memberikan solusi dari kebutuhan debitur produktif dalam mengelola bisnisnya.

Melalui teori socio-historical context, Saeed menyimpulkan bahwa semua ayat pelarangan riba ditujukan pada kreditur yang memberi pinjaman kepada debitur konsumtif. Al-Qur'ân menegasikan praktik ini sebagai bentuk perlindungan Islam atas kelompok lemah (mustad'afin) agar terhindar dari tambahan beban penderitaan. Pada kasus ini solusi yang ditawarkan al-Qur'ân menurut Saeed ialah sedekah dan zakat. Dari identifikasi semacam ini, Saeed menilai nass. larangan riba hanya berlaku bagi debitur konsumtif, dan tidak bagi orang kaya yang bertujuan untuk mengembangkan perekonomiannya. Alasannya, karena orang mampu tidak berada dalam kondisi yang memerlukan perlindungan supaya terhindar dari tambahan beban penderitaan. Saeed menyimpulkan praktik sistem bunga pinjaman dalam perbankan konvensional ditujukan bagi debitur produktif, sehingga tidak termasuk yang menimbulkan efek negatif dari

20 Pinjaman "produktif" adalah pinjaman yang dipergunakan oleh seorang yang berusaha mencari tambahan modal untuk mengembangkan usahanya. Adapun pinjaman "konsumtif" adalah orang lemah yang perlu pinjaman bank karena tidak mampu mencukupi kebutuhan pokok dirinya tanpa hal tersebut. Abdullah Saeed, Islamic Banking and Interest: A Study of the Probibition of Riba and its Contemporary Interpretation (New York: Brill, 1999), 42-44. 
penerapan bunga, yaitu ketakadilan dan penindasan terhadap kelompok lemah. Oleh karenanya, praktik bunga bank tidak termasuk riba yang dilarang, terlebih lagi dalam perjalanannya, perbankan selalu berada dalam pengawasan undang-undang yang menjamin hak semua pihak yang terhubung. ${ }^{21}$

Pemikiran Saeed tentang legalisasi bunga bank konvensional berdasar teori socio-historical context ternyata tidak jauh berbeda dengan gagasan yang pernah dilontarkan oleh pemikir modernis lain, seperti Fazlur Rahman ataupun Khaled Abou El Fadl. Lebih jauh, interprettasi Saeed secara langsung akan menggulirkan paradigma baru dalam menyikapi perbedaan bank sharî́ah dan konvensional. Pola pikir Saeed terlihat terpengaruh oleh konsep HAM modern, sehingga ia memperlakukan sama antara konsep keadilan dalam perspektif HAM dan Islam. Selain itu, ide ini tampak seperti mengadopsi unsur rasionalitas dan konsep keuntungan dari teori kapitalisme modern, sehingga golongan pemilik modal (borjuis) memiliki keistimewaan bahkan dalam hukum agama. Namun terlepas dari itu semua, tidak dapat dipungkiri bahwa pendekatan kontekstual memang diperlukan, karena ia merespons tantangan teknologi, sosial, ekonomi, keagamaan, kultural ataupun masuknya nilai-nilai "asing" sebagai akibat dari perkembangan pengetahuan modern.

\section{Rasionalisme Pemikir Islam Modern}

Saeed memberi nama bab pertama pada karyanya Islamic Thought: An Introduction dengan transmission of religious knowledge and Islamic thought. Bagi penulis, kata transmission adalah rangkaian sanad (transmisi) keilmuan yang dimulai dari sumber utama hingga penerima terakhir. Saeed tampak merumuskan hierarki ini ke dalam beberapa fase, di antaranya: a) fase awal dimulai dari al-Qur'ân yang diturunkan kepada Nabi Muhammad, diteruskan kepada sahabat. Karakteristik utama di fase ini adalah penafsiran Rasul hanya pada wilayah di mana para sahabat (companions/șaḩâbah) tidak memahami kandungan makna ataupun fakta historis dari suatu ayat; b) fase sahabat mewariskan pengetahuannya kepada para successor (tâbi ûn). Fase ini diwarnai dengan kegiatan hadîth collectors dan permasalahan bentuk sosial politik masyarakat Muslim; ${ }^{22}$ dan c) fase yang diwarnai oleh groups with diverse theological or religio-political orientations emerged (kelompok yang

\footnotetext{
${ }^{21}$ Ibid., 44-50.

${ }^{22}$ Saeed, Islamic Thought, 5-6.
} 
berbeda tujuan dalam paradigma teologi atau politik agama). ${ }^{23}$ Dari ketiga fase tersebut, periode kedua merupakan kondisi yang menarik bagi Saeed, di situ ia berujar bahwa problems among Muslims were not simply about political leadership but also about what and who represented religious authority. ${ }^{24}$ Melalui ungkapan what and who represented religious authority, Saeed seakan ingin menekankan akan adanya suatu keraguan Muslim zaman itu tentang kriteria apa, bagaimana serta siapa yang mampu secara baik merepresentasikan dan mewakili otoritas keagamaan dalam Islam. Hal inilah yang memicu lahirnya fase ketiga, yaitu fase yang diwarnai oleh perbedaan pandangan dalam berbagai masalah agama antar-kelompok, sebagai akibat logis adanya keragu-raguan pada fase sebelumnya. Tak jarang perbedaan penyikapan atas keraguraguan ini melahirkan sikap saling mem-bid'ah-kan antara satu kelompok dengan yang lain. ${ }^{25}$

Pertanyaan selanjutnya, siapa dan apa kriteria untuk dapat disebut "kompeten" dan mampu merepresentasikan serta mewakili otoritas pemikir Islam? Untuk menjawab soal ini perlu kembali melihat isi kandungan bab kedua dan tiga, dari karya Saeed yang berjudul Islamic Thought: An Introduction. Meskipun di situ Saeed hanya secara umum berbicara tentang perbedaan metode penafsiran tekstual, semi tekstual dan kontekstual, namun ada satu poin penting, yaitu pembagian Saeed atas Muslim menjadi tiga: Sunnî, Khârijî, dan Shî‘ah. ${ }^{26}$ Ketiganya memiliki karakteristik penafsiran yang beda. Sayangnya, ia tidak menjabarkan ketiganya dalam bab ini secara mendalam dan detail, ia hanya menyinggung corak corak penafsiran Sunnî saja dangan mengelaborasinya lebih dalam daripada dua fase yang lain. Berikut penuturan Saeed terkait kelompok Sunnis:

Emphasis on literal interpretation of the Qur'an wherever possible, strongly justified by linguistic evidence; reliance on tradition in explaining the text; use of reason within limits; rejection of esoteric meanings as unjustifiable speculation; respect for the Companions of the Prophet collectively as the most important source of religious authority after the Prophet; acceptance of a set of theological positions on God's attributes, religious doctrines, prophecy and revelation, the definition of a 'believer' (Muslim), and sources of

\footnotetext{
${ }^{23}$ Di antara kelompok-kelompok tersebut: Khawârij, Shî‘ah, Qadarîyah, Mu'tazilah, Jabarîyah dan Murjíah. Ibid., 7.

${ }^{24}$ Ibid., 6.

${ }^{25}$ Ibid., 8-10.

${ }^{26}$ Ibid., 27.
} 
authority in law; and rejection of positions held by rationalist theologians known as Mu'tazili. ${ }^{27}$

Terlepas dari seluruh kriteria yang tercantum, ada satu hal yang mengusik pikiran penulis setelah membaca matrik tersebut, yaitu penilaian Saeed bahwa kaum rasionalis teologis dalam Islam adalah Mu'tazilah, sekaligus menilai kaum Sunnî menolak rasionalitas. Di bagian lain Saeed juga menegaskan bahwa seorang cendekiawan dalam menafsirkan al-Qur'ân perlu untuk an affinity with rationalist thinkers in early Islam, such as the Mu'tazilis dan membacanya melalui perspektif scientific worldview. ${ }^{28}$ Jadi pemilik otoritas yang mampu merepresentasikan ide-ide pemikiran keislaman ialah mereka para pemikir rasionalis, atau dalam bahasa Saeed disebut pemikir progresif (the progressive ijtihadists). ${ }^{29}$ Kelompok inilah yang Saeed maksud dengan kelompok penggagas modernisasi pemikiran dalam Islam. Mereka berijtihad melalui interpretasi kontekstual al-Qur'ân guna menjawab tuntutan zaman.

Sampai di sini dapat disimpulkan bahwa pendekatan yang Saeed suguhkan merupakan pendekatan interkoneksi teks-konteks yang secara jelas nampak melalui pernyataannya, context-based ijtibad as it exists today should be seen as a relatively new phenomenon. Adapun model penafsiran dengan pendekatan ini ia sebut fresh interpretation. Tentang siapa pemilik hak menggunakan model interpretasi tersebut, bagi Saeed mereka kelompok pemikir modernis progresif dengan corak khasnya yang rasionalis, sehingga jawaban dari kriteria apa yang harus dimiliki untuk dapat merepresentasikan otoritas keislaman dengan kemampuan menerapkan aspek rasio dalam membaca aspek-aspek kontekstual dalam al-Qur'ân dan menerapkannya ke dalam fenomena kekinian.

\section{Modernisasi tanpa Kata Final}

Dalam Interpreting the Qur'an: Towards A Contemporary Approach, Saeed menegaskan bahwa "pisau bedah" kandungan makna teks yang terbaik adalah pendekatan yang mampu mengakomodir segala aspek sosio-historis serta kebutuhan umat yang ada alias kontekstual. Ungkapan senada dengan ini juga dapat dijumpai dalam beberapa pernyataan tokoh modernis Islam lainnya, terutama Fazlur Rahman, salah satunya:

\footnotetext{
${ }^{27}$ Ibid., 28.

${ }^{28}$ Ibid., 30.

${ }^{29}$ Ibid., 142-154.
} 
The implementation of the Qur'an cannot be carried out literally in the context of today because this may result in thwarting the very purposes of the Qur'an, and that, although the findings of the fuqaha [jurists] or the ulama [scholars] of Islam during the past thirteen centuries or so should be seriously studied and given due weight, it may well be found that in many cases their findings were either mistaken or sufficed for the needs of that society but not for today. ${ }^{30}$

Kemiripan ide Rahman dengan Saeed dapat dimaklumi, sebab sebagaimana Saeed telah dengan mantap menegaskan bahwa Rahman memang memberikan kontribusi besar dalam penafsiran ayat-ayat ethico-legal-nya. Ia tertarik dengan fokus utama Rahman yang terletak pada perhatiannya terhadap kandungan teks, supaya mampu beradaptasi dengan constantly changing environment. ${ }^{31}$

Di samping itu, Saeed melihat bahwa masalah utama mayoritas umat Islam mengklaim bahwa produk ijtihad para ulama klasik khususnya dalam fiqh sudah "final." Fenomena ini berdampak pada meningkatnya kecenderungan untuk merujuk pada karya peninggalan ulama klasik, dibandingkan langsung kepada al-Qur'ân sebagai undang-undang dasar, guna digali lebih mendalam tentang makna dan kandungan yang sesuai dengan konteks sosial masa kini. Padahal produk penafsiran ulama Klasik, yang menurut Saeed secara sosiokultur, nilai sejarah dan kondisinya sangat berbeda dengan masa kini, tentunya menghasilkan kesimpulan yang sedikit banyak tidak sesuai dengan kebutuhan masyarakat pada masa kini. ${ }^{32}$ Oleh karenanya, setiap kali ada persoalan baru yang muncul, para ulama Kontemporer akan kesulitan mencari jawaban dengan hanya sekadar merujuk pada karya para pendahulunya. Lebih parah lagi, hal ini telah secara tidak langsung memicu kejumudan dalam perkembangan keilmuan Islam. Oleh sebab itu, Saeed secara tegas menyatakan, modernists called for systematic thinking about Islamic legal issues without claiming finality. ${ }^{33}$

Statemen without claiming finality Saeed tampak baik, bijak, menunjukkan semangat dan penuh akan potensi untuk menumbuhkembangkan disiplin keilmuan Islam. Penulis menilai semangat yang ditunjukkan Saeed sebagai sebuah potensi yang akan memacu perkembangan keilmuan Islam, dengan catatan selama wilayah

${ }^{30}$ Fazlur Rahman, "The Impact of Modernity on Islam", Journal of Islamic Studies, Vol. 5, No. 2 (Juni 1966), 127.

31 Saeed, The Qur'an, 224.

32 Saeed, Interpreting the Qur'an, 152.

${ }^{33}$ Saeed, Islamic Thought, 54. 
diskusinya adalah fiqh (ijtihâdì) ataupun masalah "baik-buruk" ataupun "benar-salah," namun tidak jika sudah masuk ke dalam wilayah pokok yang bersifat tetap (al-thawâbit); haqq-bâtill. Terlebih lagi, jika yang dimaksud dengan without claiming finality sebagai sebuah pernyataan bahwa kebenaran yang diungkap oleh seorang penafsir tradisional merupakan kebenaran yang absah, maka apa yang dinilai benar oleh penafsir modern walaupun bertentangan dengan interpretasi sebelumnya, juga merupakan kebenaran yang sama-sama valid. Benar zaman dulu belum tentu benar pada masa kini.

Hal semacam ini akan melahirkan perspektif bahwa beberapa kebenaran yang berbeda atau bahkan bertolak belakang sama-sama valid. Ungkapan seperti ini dalam istilah Fazlur Rahman dikenal dengan double movement atau double truth milik Ibn Rushd. ${ }^{34}$ Menyikapi perspektif semacam ini, penulis menilai ada sebuah ungkapan yang cukup menarik yang ditulis oleh al-Attas, baginya:

Pandangan tentang adanya keberbagaian kebenaran yang sama-sama absah dalam keberbagaian dan keragaman agama mungkin berkaitan dengan penyataan dan kesimpulan filsafat dan sains modern. Filsafat dan sains modern tersebut timbul sejak ditemukannya keberbagaian dan keragaman hukum yang mengatur alam, yang di dalamnya setiap hukum memiliki tingkat kebenaran yang sama dalam setiap sistem kosmologi. Adanya tren untuk menyamakan penemuan sains tentang sistem yang terdapat dalam alam dengan penyataan yang diaplikasikan kepada masyarakat, budaya dan norma-norma adalah satu di antara ciri utama kehidupan modern. ${ }^{35}$

Jika dihubungkan antara perspektif Saeed dengan pernyataan alAttas tersebut, maka dapat dikatakan bahwa apa yang Saeed sebut sebagai level of probability dalam kebenaran, ${ }^{36}$ hanya sebuah spekulasi filosofis, ataupun sebatas pembenaran kosmologis belaka. Meskipun

34 Fazlur Rahman, Islam and Modernity: Transformation of an Intellectual Tradition (Bandung: Pustaka, 1985), 7, 22-23. Suha Taji-Farouki (ed.), Modern Muslim Intellectuals and The Qur'an (New York: Oxford, 2006), 57. Erwin Fahlbusch, et. al. (ed.), The Encyclopedia of Christianity, Vol. 2 (Germany: Brill, 1997), 766. M. Mahdi, "Averroes on Divine Law and Human Wisdom" dalam J. Corspsey, Ancient and Modern (New York: t.tp., 1964), 118. Anna Akasoy, et. al. (ed.), Renaissance Averroism and Its Aftermath: Arabic Philosophy in Early Modern Europe (New York: Springer, 2010), 214.

35 Syed Muhammad Naquib al-Attas, Prolegomena to the Metaphysics of Islam: An Exposition of the Fundamental Elements of the Worldview of Islam (Kuala Lumpur: ISTAC, 1995), 8-9.

36 Saeed, Interpreting the Qur'an, 133. 
Saeed sering menyinggung bahwa Islam sebagai satu kesatuan utuh yang mencakup ajaran yang universal, serta mencakup seluruh aspek dan norma bagi kehidupan manusia, dengan segala kondisi dan situasi, namun dalam pelaksanaannya ia terlihat mengotak-kotakkan Islam menjadi beberapa aspek yang terpisah. Artinya, Saeed hanya sebatas melihat Islam sebagai suatu ajaran yang berusaha memenuhi segala contemporary concerns dan needs of Muslims today. ${ }^{37}$

Lahirnya anggapan tentang perbedaan level of probability ala double truth tentang suatu kebenaran yang dicapai, ${ }^{38}$ pastinya merupakan dampak logis dari suatu hal. Penulis memahami hal ini sebagai akibat dari adanya perbedaan pandangan tentang sampainya pemahaman antara pembicara dan lawan bicara, penulis dan pembaca, teks dan interpreter. Menjelaskan hal ini Barbara A. Holdrege menilai, bahwa hubungan antara pembicara dan pendengar merupakan relasi personal, adapun penulis (author) dengan pembaca adalah impersonal. Pada relasi personal telah terjadi kontak secara langsung antara reader dengan author/speaker. Adapun kontak yang terjadi pada kondisi yang disebut belakangan diwakili oleh teks yang tertulis. ${ }^{39}$ Oleh sebab itu penafsiran kandungan makna dari sebuah teks menjadi impersonal, atau tepatnya relasinya bukan lagi menjadi antara pembaca dengan author, namun antara pembaca dengan inpersonal text. ${ }^{40}$ Untuk lebih jelasnya, berikut ungkapan Paul Ricoeur mengenai hubungan antara penulis, teks dan pembaca: the reader is absent from the act of writing, the writer is absent from the act of reader. The text thus produces a double eclipse of the reader and the writer. It thereby replace the relation of dialogue, which directly connects the voice of one to the hearing of the other. ${ }^{41}$

Dari pernyataan Ricoeur, dapat dikatakan bahwa sifat kebenaran, pemahaman ataupun pengetahuan yang didapat oleh pembaca tidak bersifat penutup (finality), sebab ada kemungkinan terjadinya dua atau lebih kebenaran yang dipahami, baik oleh author maupun reader. Atas

${ }^{37}$ Ibid., 1. Saeed, Islamic Thought, 32.

38 Saeed, Interpreting the Qur'an, 133.

${ }^{39}$ Barbara A. Holdrege, Veda and Torah: Trancending the Textuality of Scrpture (Albany: State University of New York Press, 1996), 418-419.

40 Saeed, Interpreting the Qur'an, 111. Yusuf Rahman, The Hermeneutical Theory of Nașr Hâmid Abû Zayd: An Analytical Study of His Method of Interpreting the Qur'an (Thesis of the Degree of Doktor of Philosophy--Institute of Islamic Studies McGill University Canada, 2001), 124.

${ }^{41}$ Paul Ricoeur, "What is a Text? Explanation and Understanding", dalam John B. Thompson (ed.), Hermeneutics and Human Sciences (Cambridge: Cambridge University Press, 1988), 146-147. 
dasar inilah, Saeed mencoba kembali ke masa lalu di mana ayat-ayat tersebut turun, mengambil esesnsi dasar dari maksud ayat, kemudian dikontekstualisir pada problem-problem kontemporer. ${ }^{42}$

Oleh sebab itu, ungkapan semacam "Muslim harus bergeser kepada yang berkaitan dengan konteks sosial, historis dan linguistik teks" secara umum memang sah-sah saja. Namun pertanyaan selanjutnya, sampai di manakah pergeseran tersebut berlangsung? Persoalan ini tidak sepele, karena dampaknya akan melahirkan persoalan baru, seperti jika ditemukan perbedaan pemahaman yang benar antara tekstual dan kontekstual, manakah yang harus dikedepankan? Menyikapi hal ini perlu ditegaskan, memang benar modernisasi pemikiran Islam muncul karena tantangan perkembangan yang dihadapi oleh umat; konteks masa awal diturunkannya wahyu juga ikut berbicara dalam upaya memahami teks tersebut, namun jika konteks menjadi faktor tunggal dari turunnya wahyu hal ini menjadi bermasalah. Sebab sebagaimana dimaklumi dalam penafsiran alQur'ân dikenal kaidah al-'ibrah bi umûm al-lafæa lâ bi khusûs al-sabab. ${ }^{43}$ Sedangkan apa yang dimaui oleh Saeed cenderung kepada lawannya,

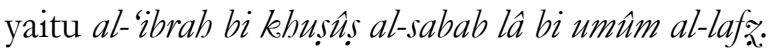

Meskipun demikian tidak bisa dipungkiri bahwa pendekatan kontekstual muncul sebagai respons atas adanya tantangan teknologi, sosial, ekonomi, keagamaan, kultural ataupun masuknya nilai-nilai "asing" sebagai akibat dari kemajuan pengetahuan modern. ${ }^{44}$ Oleh karena itu, perlu suatu pernyataan bahwa "adanya perubahan suatu kondisi tidak mewajibkan perubahan makna kandungan suatu teks." Sebab sebagaimana diketahui bahwa Islam memiliki watak ajaran yang universal. Ia mencakup seluruh aspek dan norma bagi kehidupan manusia, baik yang berkaitan dengan persoalan ritual maupun sosial. Dari segi waktu, Islam berlaku sepanjang zaman, dari aspek pemeluk ia berlaku untuk seluruh umat manusia tanpa dikotak-kotakkan ke dalam etnis, budaya maupun geografi.

Dalam masalah penafsiran sebagaimana dijelaskan di atas, secara umum Saeed menilai bahwa kesempatan untuk melakukan reinterpretasi masih tetap terbuka. Karenanya, ia menghimbau seluruh

${ }^{42}$ Saeed, Islamic Thought, i, vii, 10, 13, 30.

43 Fakhr al-Dîn al-Râzî, Mafâtị̣ al-Ghayb, Vol. 3 (Beirut: Dâr Ihyâ' al-Turâth al'Arabî, 1420 H), 496, 503. Ibrâhîm b. Ismâ'îl al-Abyârî, al-Mawsû̀'ah al-Qur'ânîah, Vol. 2 (t.t.: Muassasah Sajal al-'Arab, 1405 H), 37.

${ }^{44}$ Achmad Jaenuri, Orientasi Ideologi Gerakan Islam Modern (Surabaya: LPAM, 2004), 94. 
cendekiawan yang memiliki otoritas keilmuan agar selalu melakukan interpretasi sepanjang masa, walaupun setiap orang pastilah memiliki kekurangan tersendiri. Terlepas dari segala kelebihan dan kekurangan, dalam perspektif penulis, setiap manusia "normal" pada hakikatnya mampu untuk mengetahui dan mengenal, memilih dan memilah, memisahkan dan membedakan, menilai dan menentukan mana yang benar dan salah, yang haqq dan bâtil, yang betul dan keliru, yang sehat dan sakit, yang sejati dan palsu, yang baik dan buruk, yang bagus dan jelek, yang ma'rûf dan munkar serta mana yang berguna dan berbahaya. Seperti halnya mampu untuk mengetahui, mengerti dan membedakan antara apa yang dimaksud dengan imân dan kufr, keadilan dan kelaliman, cahaya dan gulita, keberuntungan dan kerugian dan lain sebagainya.

Apa yang dimaksud penulis dengan "kekurangan" lebih kepada adanya keterbatasan intrinsik maupun ekstrinsik yang terdapat dalam diri manusia. Adapun apa yang dimaksud kondisi "normal" merupakan suatu keadaan seorang yang tidak cacat dan tidak sakit ataupun terganggu fisik dan mentalnya, jasad maupun rohnya terutama sekali akal dan hatinya. Selanjutnya, kata "mampu" di sini mewakili kapasitas manusia, baik secara lahir, batin, mental dan spiritual dengan segala bentuk dan rupanya. Kekurangan ataupun keterbatasan yang inherent dalam diri manusia memang tidak dapat dipungkiri, namun tidak harus sampai berakibat menggugurkan nilainilai keberakhiran dalam kebenaran ataupun validitas suatu pengetahuan yang didapatinya. Akhirnya dapat dikatakan bahwa kondisi normal yang didukung dengan kemampuan seseorang, meskipun dibayangi kekurangan selama poin terakhir tidak merusak dua hal yang disebutkan pertama tidak akan merubah nilai kebenaran yang didapat.

Lebih jauh, jika dikaitkan dengan istilah filsafat modern, maka pertanyaan Kant, how is knowledge possible? ${ }^{45}$ Dapat dijawab melalui sekian banyak proses elaborasi. Rangkaian proses tersebut meliputi: proses persepsi indra (idrâk al-ḥawâs), akal sehat (ta'aqu), intuisi kalbu (al-hadth) dan informasi yang benar (al-khabar al-șâdiq). ${ }^{46}$ Secara

\footnotetext{
${ }^{45} \mathrm{Hal}$ ini dibahas mendetail oleh filsuf Jerman bernama Immanuel Kant, Prolegomena to Any Future Metaphysics, Paul Carus (ed.) (New York: Open Court, 1949), 2, 5, 6-11. 46 Sa'd al-Dîn al-Taftâzânî, Sharh al-'Aqâ'id al-Nasafîyah (Istanbul: al-Matba'ah al'Uthmânîyah, 1308 H), 29. Adi Setia, "Epistemologi Islam Menurut al-Attas Satu Uraian Singkat" dalam Islamia: Jurnal Pemikiran dan Peradaban Islam, Vol. 2, No. 6
} 
singkat, rangkaian prosesnya mencakup; persepsi lima indra (penglihatan, pendengaran, perasa, pembau dan sentuhan), dilengkapi dengan al-hiss al-mushtarak atau sensus communis, yang menyertakan daya ingatan atau memori (dhâkirah), daya imajinasi (khayâl) dan daya estimasi (wahm). ${ }^{47}$ Proses akal ini mencakup nalar (nazar) dan alur pikir (tafkir). ${ }^{48}$ Dengan penalaran dan alur pemikiran seseorang mampu untuk berartikulasi, menyusun proposisi, menyatakan pendapat, berargumentasi, melakukan analogi, membuat putusan serta menarik suatu kesimpulan. Adapun melalui intuisi kalbu manusia "sempurna" akan mampu menangkap pesan dan isyarat ghâyb serta mendapatkan ilhâm, mushâhadah, kashf, dan sebagainya. Adapun khabar sâdiq-yang berasal dari dan bersandar pada otoritas, apalagi dalam urusan agama adalah wahyu yang diterima dan diteruskan melalui proses transmisi (riwâyah) dan transfer (naq) dari satu generasi ke generasi selanjutnya. Jadi membaca khabar șâdiq bukan semata-mata hanya menafsirkan teks melalui interpretasi logis, namun harus didahului dengan pembacaan melalui pancaindra, proses akal sehat dan dilengkapi dengan penegasan melalui intuisi. Barulah kesesuaian antara teks, konteks dan makna sejati darinya akan terkuak. Akhirnya, penutup (finality) dalam suatu pengetahuan ataupun penafsiran dapat diperoleh. Hal semacam ini pernah diungkapkan oleh al-Attas dalam karyanya Prolegomena to the Metaphysics of Islam: Islam affirms the possibility of knowledge; that knowledge of realities of things and their ultimate nature can be established with certainty by means of our external internal sense and faculties, reason and intuition, and the true report of scientific or religion nature, transmitted by their authentic authorities. $^{49}$

Penulis setuju dengan ungkapan Saeed tentang without claim of finality selama hal itu berada dalam wilayah ijtihâdî́, namun tidak jika sudah meluas ke dalam wilayah ussûlí. Sebab mengetahui dengan benar, valid dan bernilai final itu tidak mustahil. Hal ini tidak sama seperti klaim kaum sofis, relativis, skeptis ataupun agnostik. Sebagaimana ditegaskan secara singkat oleh al-Nasafî: Haqâ'iq al-ashâ'iy thâbitah, wa

(Juli-September 2005), 54. Mulyadhi Kartanegara, Menyibak. Tirani Kejabilan: Pengantar Epistemologi Islam (Bandung: Mizan, 2005), 21.

47 Abû Hâmid al-Ghazâlî, Máârij al-Quds ilâ Madârij Ma'rifat al-Nafs (Beirut: t.tp., 1978), 44-47.

${ }^{48}$ Fakhr al-Dîn al-Râzî, Mụạssal Afkâr al-Mutaqaddimîn wa al-Muta'akbkhirîn (Kairo: al-Matba'ah al-Qusaynîyah, t.th.), 23, 30.

49 al-Attas, Prolegomena to the Metaphysics of Islam, 14. 
al-ïm bihâ mutahaqqiq, khilâfan li al-sûfatâîyah. ${ }^{50}$ Konotasinya bahwa hakikat ataupun esensi segala sesuatu itu tetap karena bisa dicapai dan tidak berubah, sebab yang berubah-ubah itu hanya sifat-sifatnya saja, sehingga segalanya bisa diketahui dengan jelas dan final.

\section{Abad Modern sebagai Keterbebasan Bermazhab}

Saeed memandang kewajiban setiap Muslim adalah mengekstrak nilai-nilai semangat perkembangan dan perubahan ke dalam kehidupan nyata. Oleh karena zaman terus berkembang, maka seorang cendekiawan Muslim harus mampu untuk melihat konteks dari hasil penafsiran serta kondisi yang ada pada masa awal Islam kemudian menerapkannya ke dalam konteks kekinian. Perbedaan penafsiran teks oleh ulama figh melahirkan perbedaan produk fiqh yang mereka hasilkan. Hal ini agaknya dalam perspektif Saeed merupakan suatu bentuk kontemplasi dalam menerjemah wahyu ke dalam kehidupan sosial bermasyarakat. ${ }^{52}$ Sebab apa yang digagasnya tidak bisa terlepas dari anggapan umum kelompok penggagas modernisasi, bahwa orientasi ideologi mereka diwarnai oleh wawasan keagamaan yang mewajibkan penerapan nilai ajaran Islam sebagai dasar bagi semua aspek kehidupan. Hal ini tidak semata-mata berkutat pada persoalan ritual, tetapi juga meliputi semua aspek kehidupan sosial kemasyarakatan. ${ }^{53}$ Saeed memandang perlu adanya suatu metode pembacaan "baru" yang mampu mengimbangi perubahan zaman, tidak semata-mata merepetisi model tradisionalis yang ada. Metode ini ia sebut sebagai fresh interpretation. ${ }^{54}$

Bagaimana kemudian menerjemahkan fresh interpretation ke dalam warisan nilai-nilai klasik agar bisa relevan dengan masa kini, tanpa terbawa mazhab yang telah ada? Sembari menekankan makna fresh, secara umum Saeed menggambarkan metodenya sebagai berikut: "menggunakan pendekatan yang masih segar (fresh) dan kontekstual serta dikomando oleh proses pembacaan objektif dan rasional". ${ }^{55}$ Objektivitas dalam arti memisahkan kondisi kekinian dan membandingkan dengan kondisi generasi Islam awal. Inti proses ini adalah dekonstruksi ataupun pembebasan diri dari asumsi-asumsi keagamaan

\footnotetext{
50 Najm al-Dîn 'Umar b. Muhammad al-Nasafî, al-'Aqâ'id, dalam Majmû' min Mubimmât al-Mutîn (Kairo: al-Mạtba'ah al-Khayrîyah, 1306), 19.

${ }^{52}$ Saeed, The Qur'an, 111-112.

53 Akbar S. Ahmed, Post Modernism and Islam (London: Routledge, 1992), 31.

${ }^{54}$ Saeed, Islamic Thought, 152. Saeed, The Qur'an, 214.

55 Saeed, Islamic Thought, 208-213.
} 
yang telah berkembang, dengan jalan memisahkan antara subjek pengkaji dan objek yang dikaji. Karenanya, sebagaimana disebut di atas, kenapa posisi author, texts dan reader sangat berperan. Adapun "rasionalitas" di sini bermakna mengontekstualkan kondisi yang berlaku pada masa lalu dan kekinian. Tahapan ini didominasi oleh proses rekonstruksi pemikiran dari data yang diperoleh setelah melewati proses objektivikasi. Tujuannya adalah mendapatkan hasil yang lebih baru, lebih fresh dan lebih kontekstual untuk setiap situasi dan kondisi. Saeed menyebut beberapa nama yang menurutnya telah melakukan hal ini, seperti: Fazlur Rahman, Amina Wadud, Muhammad Shahrour, Muhammad Arkoun dan Khaled Abou El Fadl. $^{56}$

Sekilas apa yang ditunjukkan Saeed di atas tampak fresh, baik, toleran dan mengakomodir kebutuhan manusia sepanjang masa. Namun jika diartikan ketertutupan (exclusivity) sebagaimana Saeed pahami sebagai keyakinan atas produk atau tradisi pemikiran yang benar, sementara yang lain salah, maka menurut John Hick secara otomatis akan melahirkan corak pikiran inklusif bermazhab. Perkembangan lebih jauh dari sikap ini adalah pluralisme akan mengakui adanya kebenaran yang sederajat dalam setiap tradisi dan kepercayaan. ${ }^{57}$ Ide Saeed secara tidak langsung tampak mirip dengan corak pemikiran dari sofisme subjektif ('indîyah). ${ }^{58}$ Baik Saeed ataupun indîyah memiliki persamaan dalam cara pandang, yaitu melihat kandungan suatu teks sebagai sebuah produk dari identitas kebudayaan dan sosio-ekonomi tertentu. Keduanya mengklaim produk penafsiran klasik atas makna suatu teks hanya sebentuk pencerminan kedudukan sosio-kultur masa lalu, yang saat itu perkembangan peradaban manusia masih sangat minim. ${ }^{59}$

Tujuan ilmu pengetahuan dan kebenaran adalah subjektif ('indîy, yaitu "menurut saya"), bergantung pada pendapat masing-masing. ${ }^{60}$

\footnotetext{
56 Ibid., 41, 139-140, 166-167. Saeed, The Qur'an, 219.

57 John Hick, "Religious Pluralism," dalam Mircea Eliade (ed.), The Encyclopedia of Religion, Vol. 11 (New York: MacMillan, 1987), 331-333.

${ }^{58}$ Kelompok al-indîyah, yaitu mereka yang selalu bersikap subjektif. Kelompok ini menerima kemungkinan ilmu pengetahuan dan kebenaran, tetapi menolak tujuan ilmu pengetahuan dan kebenaran. Syed Muhammad Naquib al-Attas, A Commentary on Huijatul Siddiq of Nur al-Din al-Raniri (Kuala Lumpur: Ministry of Culture, 1986), 206-207.

${ }^{59}$ Saeed, The Qur'an, 221-222

60 Al-Attas, A Commentary on Huijatul Siddiq, 206-207.
} 
Berangkat darinya timbul beberapa ungkapan semisal: "problematika peradaban modern jauh lebih kompleks dari masa lampau;" "cara pandang tradisional hanya mewakili framework masa itu;" "zaman terus berganti karenanya kebutuhan manusia akan metode penafsiran juga harus mengikuti perubahan zaman" dan sebagainya. Oleh sebab itu, sudah menjadi kewajiban tiap Muslim untuk kembali memahami agama Islam khususnya al-Qur'ân dan sunnah dan tidak merasa pendapatnya benar sendiri. Poin pentingnya, kandungan makna yang terdapat di dalam teks dalam perspektif Saeed harus bisa untuk disesuaikan dengan perubahan kekinian.

Bagi penulis, tantangan perubahan kultural yang dihadapi alQur'ân atau Islam secara umum tidaklah bisa untuk digeneralisir begitu saja. Adanya perbedaan sekaligus persamaan dalam hal hukum, etika, estetika serta prinsip-prinsip keilmuan atau bahkan teologi dalam kaitannya dengan budaya, disebabkan fakta bahwa kesemuanya berasal dari Tuhan, bukan sebatas hasil kreativitas manusia. Secara fair dapat dikata bahwa kelebihan zaman kekinian dibandingkan masa Nabi silam hanya sebatas pada aspek kuantitatif dari penemuan teknologi, ataupun bentuk problematika yang ada. Adapun anggapan bahwa kemampuan cendekiawan Muslim sekarang mampu mengimbangi bahkan melebihi prestasi para pendahulunya masih sangat diragukan, meskipun hanya sebatas pada kuantitas penemuan teknologi dan keterampilan yang ditunjukkan. Karenanya, bagaimana mungkin seseorang yang tidak lebih baik dari pendahulunya akan mampu menghasilkan suatu cara pandang yang lebih tepat, berkelas, komprehensif serta lebih mengena? Jadi ungkapan semacam: "modernisasi harus terbebas dari keterikatan dengan suatu mazhab pemikiran terdahulu" masih dirasa janggal.

Di samping itu, keterlepasan dari eksklusivitas bermazhab tidak menjadi jaminan akan adanya objektivitas dalam interpretasi. Terlebih lagi, kontekstualisasi penafsiran modern-menurut penulismeskipun oleh Saeed selalu digadang pasti terlepas dari eksklusivitas mazhab ataupun sekte, pada akhirnya hanya merupakan suatu manifestasi dari sofisme modern dan terjebak dalam lingkaran aliran baru, "mazhab tanpa mazhab". Untuk melihat apakah eksklusivitas selalu berakhir tidak baik atau bahkan bisa lebih baik dari inklusivitas. Sebagai contoh, "dalam dunia pendidikan seringkali terdengar ungkapan bahwa porsi mata pelajaran disiplin ilmu pengetahuan dan ilmu agama harus dianggap sama, tidak boleh ada eksklusivitas satu 
dengan yang lain. Kajian tentang teologi Islam misalnya, disamakan dengan ilmu-ilmu komputer ataupun jual beli”. Secara filosofis hal semacam ini dapat dikatakan sah-sah saja, namun jika dibedah dari sisi metafisika Islam, maka tidak sepatutnya semua mata pelajaran dianggap sama. Sebab setiap pelajaran memiliki konsentrasi dan prioritas bahasan tersendiri. Meskipun keduanya penting, namun apakah sama antara pelajaran tentang aqîdah (dasar fondasi Islam) dengan pelajaran mengoperasikan komputer? Bagitu halnya dengan "ekskluvitas mazhab", di mana sikap semacam ini tampak lebih prima facie, toleran, kontekstual dan lebih bermanfaat, tetapi kenyataannya jika ditelisik lebih mendalam akan tampak bahwa sikap ini tidak berhasrat untuk memahami perbedaan pemikiran yang ada, skala prioritas menjadi nihil dan semua hal menjadi bernilai sama, kesemuanya ini tidak lain disebabkan oleh ketidakyakinan mereka terhadap otoritas keilmuan mereka sendiri.

Dari penjelasan di atas, dapat disimpulkan bahwa meskipun secara bahasa sikap antieksklusif mengandung "maksud" baik, namun dalam pelaksanaannya masih sangat mungkin untuk mengandung suatu makna tersembunyi yang dipahami dan diterapkan secara konkret mengikuti keunikan zaman dan bangsa. Pada akhirnya hal ini malah akan melahirkan apa yang disebut sebagai tafsir lokal, lama, dan baru bahkan dalam sekala yang lebih luas Islam lokal, Islam Indonesia, Islam Arab dan sebagainya. Hal semacam ini merupakan suatu bentuk pribumisasi (indigenization) penafsiran al-Qur'ân khususnya, ataupun Islam secara umum. ${ }^{61}$ Pola pemikiran semacam ini secara tidak langsung telah menghapuskan elemen-elemen Islam yang universal (kulli), alias deconstruction of values, dan menjadikan Islam menjadi terkotak-kotak sesuai zaman, bahasa, fisik epitemis dan sebagainya.

\section{Penutup}

Gagasan Abdullah Saeed bukan tanpa cela, karena modernisasi pemikiran bukan berarti harus merdeka dari otoritas masa lalu ataupun harus mutlak melihat pada konteks situasi dan kondisi. Halhal semacam teks, konteks, metode pembacaan, bingkai kerja (framework) pembaca dan ataupun maksud author memainkan peran penting selama tidak menyalahi satu sama lainnya. Elemen-elemen

${ }^{61}$ Mohammad Yusuf Siddiq, Epigraphy and Islamic Culture: Inscriptions of the Early Muslim Rulers of Bengal (New York: Routledge, 2016), 67-69. John Renard, Islam and the Heroic Image: Themes in Literature and the Visual Arts (Georgia: Mercer University, 1999), 14. 
tersebut menunjukkan kekhasan prinsip dasar epistemologi Islam. Karenanya, tidak boleh hanya mengedepankan konteks di atas unsur lain, sebab pengagungan kontekstualisasi akan mengaburkan makna dari teks itu sendiri. Hal itu juga malah akan mendorong apa yang disebut sebagai tafsir lokal, tafsir lama dan baru bahkan dalam sekala yang lebih luas Islam lokal, Islam Indonesia, Islam Arab dan sebagainya. Selain itu, elemen-elemen pengetahuan lain semacam arti mengetahui, sumber pengetahuan, objek kajian serta validitas ataupun penutup pengetahuan tidak bisa dikatakan terus berubah, karena dalam agama ada hal-hal yang bersifat tetap (al-thawâbit). Oleh sebab itu dalam mencari kebenaran dari suatu kandungan teks, Muslim diperintahkan berhati-hati dan kritis dengan melakukan screening atau check and recheck. Oleh karena itu, dapat disimpulkan bahwa kemajuan ataupun kemunduran sains dipengaruhi oleh dan tergantung pada banyak faktor internal maupun eksternal, bukan semata-mata konteks yang berlaku, sehingga fresh interpretation tidak menuntut harus baru dan berbeda dengan interpretasi generasi awal.

\section{Daftar Rujukan}

Abyârî̀ (al), Ibrâhîm b. Ismâ'îl. al-Mawsû'ah al-Qur'ânîah, Vol. 2. t.t.: Muassasah Sajal al-'Arab, $1405 \mathrm{H}$.

Ahmed, Akbar S. Post Modernism and Islam. London: Routledge, 1992.

Akasoy, Anna et. al. (ed.). Renaissance Averroism and Its Aftermath: Arabic

Philosophy in Early Modern Europe. New York: Springer, 2010.

al-Attas, Syed Muhammad Naquib. A Commentary on Hujjatul Siddiq of

Nur al-Din al-Raniri. Kuala Lumpur: Ministry of Culture, 1986.

----. Prolegomena to the Metaphysics of Islam: An Exposition of the Fundamental Elements of the Worldview of Islam. Kuala Lumpur: ISTAC, 1995.

Birberick, Anne L. et. al. Modern Perspectives on the Early Modern: Temps Recherché, Temps Retrouvé. Virginia: Rookwood Press, 2005.

Brown, Gillian et. al. Discourse Analysis. Cambridge: Cambridge University, 1984.

Fahlbusch, Erwin et. al. (ed.) The Encyclopedia of Christianity, Vol. 2. Germany: Brill, 1997.

Ghazâlî (al), Abû Hâmid. Máârij al-Quds ilâ Madârij Márifat al-Nafs. Beirut: t.tp., 1978.

Goldziher, Ignaz. Madhâhib al-Tafsîr al-Islâmî. Kairo: Maktabah alKhaniji, 1955. 
Hick, John. "Religious Pluralism," dalam Mircea Eliade (ed.), The Encyclopedia of Religion, Vol. 11. New York: MacMillan, 1987.

Holdrege, Barbara A. Veda and Torab: Trancending the Textuality of Scrpture. Albany: State University of New York Press, 1996.

Jaenuri, Achmad. Orientasi Ideologi Gerakan Islam Modern. Surabaya: LPAM, 2004.

Kant, Immanuel. Prolegomena to Any Future Metaphysics, Paul Carus (ed.). New York: Open Court, 1949.

Kartanegara, Mulyadhi. Menyibak Tirani Kejabilan: Pengantar Epistemologi Islam. Bandung: Mizan, 2005.

Mahdi, M. "Averroes on Divine Law and Human Wisdom" dalam J. Corspsey, Ancient and Modern. New York: t.tp., 1964.

Marius, Richard (int.). Random House Webster's College Dictionary. New York: McGraw-Hill, 1991.

Mawardi, Ahmad Imam. "Muslim Progresif dan Ijtihad Progresif dalam Pandangan Abdullah Saeed," dalam Tolhatul Choir, Islam dalam Berbagai Pembacaan Kontemporer. Yogyakarta: Pustaka Pelajar, 2009.

Nasafî (al), Najm al-Dîn 'Umar b. Muhammad. al-'Aqâ'id, dalam Majmû́ min Mubimmât al-Mutinn. Kairo: al-Mạtba'ah al-Khayrîyah, 1306.

Noer, Deliar. Gerakan Modern Islam di Indonesia 1900-1942. Jakarta: LP3S, 1996.

Rahman, Fazlur. "The Impact of Modernity on Islam", Journal of Islamic Studies, Vol. 5, No. 2, Juni 1966.

-----. Islam and Modernity: Transformation of an Intellectual Tradition. Bandung: Pustaka, 1985.

Rahman, Yusuf. The Hermeneutical Theory of Nașr Hâmid Abû Zayd: An Analytical Study of His Method of Interpreting the Qur'an. Thesis of the Degree of Doktor of Philosophy--Institute of Islamic Studies McGill University Canada, 2001.

Râzî (al), Fakhr al-Dîn. Mafâtiḥ al-Ghayb, Vol. 3. Beirut: Dâr Ihyâ' alTurâth al-'Arabî, $1420 \mathrm{H}$.

----. Muhașsal Afkâr al-Mutaqaddimîn wa al-Muta’akbkhirîn. Kairo: alMatba'ah al-Qusaynîyah, t.th.

Renard, John. Islam and the Heroic Image: Themes in Literature and the Visual Arts. Georgia: Mercer University, 1999. 
Ricoeur, Paul. "What is a Text? Explanation and Understanding", dalam John B. Thompson (ed.), Hermeneutics and Human Sciences. Cambridge: Cambridge University Press, 1988.

Saeed, Abdullah. Interpreting the Qur'an: Towards A Contemporary Approach. New York: Routledge, 2006.

----. Islamic Banking and Interest: A Study of the Probibition of Riba and its Contemporary Interpretation. New York: Brill, 1999.

----. Islamic Thought: An Introduction. New York: Routledge, 2006.

----- Reading the Qur'an in the Twenty-First Century: A Contextualist Approach. New York: Routledge, 2013.

----. The Qur'an: An Introduction. New York: Routledge, 2008.

Setia, Adi. "Epistemologi Islam Menurut al-Attas Satu Uraian Singkat" dalam Islamia: Jurnal Pemikiran dan Peradaban Islam, Vol. 2, No. 6, Juli-September 2005.

Siddiq, Mohammad Yusuf. Epigraphy and Islamic Culture: Inscriptions of the Early Muslim Rulers of Bengal. New York: Routledge, 2016.

Stillar, Glenn F. Analyzing Everyday Texts: Discourse, Rhetoric, and Social Perspectives. London: SAGE, 1998.

Syafe'ie, Imam. Retorika dalam Menulis. Jakarta: Dependikbud, 1988.

Taftâzânî (al), Sa'd al-Dîn. Sharh al-'Aqâid al-Nasafîyah. Istanbul: alMatba'ah al-'Uthmânîyah, $1308 \mathrm{H}$.

Taji-Farouki, Suha (ed.). Modern Muslim Intellectuals and The Qur'an. New York: Oxford, 2006.

Warren, Paul et. al. (ed.) Context and Semantics for Knowledge Management. New York: Springer, 2011. 